\title{
Smart Construction Objects
}

\author{
Yuhan $\mathrm{Niu}^{1}$, Weisheng $\mathrm{Lu}^{2 *}$, Ke Chen ${ }^{3}$, George G. Huang ${ }^{4}$, and Chimay Anumba ${ }^{5}$ \\ 1 Ph.D. Candidate, Department of Real Estate and Construction, The University of Hong Kong. Email: \\ yuhanniu@connect.hku.hk \\ 2 Assistant Professor, Department of Real Estate and Construction, The University of Hong Kong. \\ (corresponding author) Email: wilsonlu@hku.hk \\ 3 Ph.D. Candidate, Department of Real Estate and Construction, The University of Hong Kong. Email: \\ leochen@connect.hku.hk \\ ${ }^{4}$ Professor, Department of Industrial and Manufacturing Systems Engineering, The University of Hong \\ Kong. Email: gqhuang@hku.hk \\ 5 Professor, Department of Architectural Engineering, The Pennsylvania State University. Email: \\ anumba@engr.psu.edu
}

\section{Abstract}

The primary aim of this research is to define smart construction objects (SCOs), the fundamental building blocks of future construction. SCOs are construction resources (e.g. machinery, device, and materials) that are made "smart" by augmenting them with technologies conferring autonomy, awareness, and the ability to interact with their vicinity. This "smartness" can enable better decision-making in construction. Understanding of SCOs, however, is still in its infancy. Informed by theories on ubiquitous computing and general smart objects, this paper firstly defines the core properties that differentiate SCOs from conventional construction objects. Secondly, representative scenarios of the use of SCOs are given to illustrate the new workflow with enhanced smartness in the future. Next, using prefabrication construction as an example, this paper further elaborates SCOs by using Industry Foundation Classes (IFC) Extensible Markup Language (XML) and exploring their software/hardware representations. This is the first-ever research to articulate canonical SCOs and their core properties, computing applications, and representations. More specific and applicable SCOs are compellingly desired as the future study. Properly linked to building information modeling (BIM) and Internet of Things (IoTs), SCOs can enable a safer, greener, more efficient, and more effective construction 
system that has ever been seen.

Keywords: Smart construction objects, construction project management, Building Information Modeling, Internet of Things

\section{Introduction}

Construction project management is the management of construction resources (e.g. manpower, materials, and machinery) to achieve project objectives relating to quality, duration, cost, and so on. Managing a construction project per se is to make a web of decisions across construction processes using available information and knowledge (Flanagan and Lu 2008). The main objective of information management is to support decision-making by ensuring that accurate information is always available at the right time in the right format to the right person (Chen et al. 2015). Recently, there has been a wealth of research into how to provide decision-makers with accurate, timely, and well-formatted information, e.g. using building information modeling (BIM) (Eastman et al., 2009; Goedert and Meadati, 2008); by adopting Information and Communication Technologies (ICT) such as Auto-ID (Jaselskis and El-Misalami 2003; Domdouzis et al. 2007; Lu et al. 2011; Flanagan et al. 2014), and sensing technology (Kawakami et al. 2008; Kolba and Collins 2006).

Underpinning this thread of research is the philosophical stance that human beings, with their intelligence and cognitive abilities, are central decision-makers; in the construction process, determining the use of construction resources such as materials and machinery. Whilst this people-centric decision-making model makes sense in construction, it must also be acknowledged that human beings are not infallible when it comes to processing 
information and making informed decisions (Reason 2000). In this context, human intelligence shows deficiencies (such as being slower and more error-prone) when compared with artificial intelligence (AI) (Sterman 1989). This resonates with Simon's (1986) bounded rationality theory, which suggests that rationality of individuals in decision-making is limited by the information, their cognitive ability, and the finite amount of time they have to make decisions. Such limitations are particularly evident in today's increasingly large and complex construction projects. The amount of information to be dealt with is increasing exponentially, resulting in problems such as quality defects, delayed delivery, and cost overrun.

This situation has given rise to the development of smart construction objects (SCOs). These are construction resources that are made "smart" by augmenting them with capabilities of sensing, processing, computing, networking, and reacting. The resulting awareness, autonomy, and ability to interact with the vicinity (on-site or off-site), facilitate better decision-making. For example, construction materials can be augmented with sensing and networking abilities to sense their surroundings and convey their real-time position information to human decision-makers, enhancing logistics and supply chain management. Construction machinery can be augmented with smartness to make sense the materials they are to handle. SCOs can also "talk" to each other directly. For example, a smart tower crane can talk to smart construction materials in order to assess potential safety hazards before hoisting the materials. Whilst these SCOs are still providing decision-making information to human decision-makers, what makes them different from conventional construction objects is that they can talk to each other directly. In doing so, some routine or clearly rule-based decisions can be made by SCOs autonomously without necessarily involving human decision-makers in the loop. 
Smart objects (SOs) have been discussed in the context of various industries and daily life. For example, Kortuem et al. (2010) define SOs as objects that sense, log, and interpret what is occurring within themselves and the world, act on their own, communicate with each other, and exchange information with people. Beigl et al. (2001) suggest that daily-life SOs emerge when everyday objects are given the added value of information processing and exchange capabilities without restricting or compromising their original appearance or function. While Zhang et al. (2011) have explored the use of SOs in the manufacturing industry, the understanding of their use in construction is limited. Most construction works are project-based with varying workflows. Their unique, non-revisable, and one-off nature does not allow for the development of standard procedure or prototypes for mass production, as normally seen in production-based industries. Undertaking construction work thus involves sophisticated decision-making based on intensive communication amongst professionals and stakeholders and, if this process fails, severe losses result. While construction is arguably the sector in which smarter resources are most urgently needed, understanding to SCOs in the construction sector is still in their infant stage. For example, it is unclear whether the heterogeneity of the construction sector requires an industry-specific definition of smart objects. The core properties that make SCOs different from their conventional counterparts are also yet to be explored in both the literature and in real-life construction practices.

The primary aim of this research is to define SCOs and explore their potential uses in the construction sector. The remainder of the paper comprises five sections. Section 2 is a review of the literature on the origins of smart objects and their applications in various industries including construction. Informed by theories on ubiquitous computing and 
general smart objects, Section 3 defines SCOs and suggests three core properties that underlie all SCOs. Section 4 describes four SCO-use scenarios (i.e. component checking, safety management, procedure guiding, and facilities management), with a view to illustrating SCOs' canonical properties, computing applications, and representation. Using prefabrication construction as a case study, Section 5 elaborates upon SCOs by exploring their design and development. A new workflow using SCOs is also illustrated. Section 6 discusses the immense challenges and opportunities presented by SCOs for future construction, and conclusions are drawn in Section 7.

\section{Literature review}

\section{Smart objects}

The idea of smart objects (SOs) originates from the concept of "ubiquitous computing" coined by the Computer Science Laboratory of the Xerox Palo Alto Research Center in early 1988. In software engineering and computer science, ubiquitous computing means that computing is made to appear everywhere and anywhere. It shifts the paradigm of "one person-one computer" to a new form whereby computers are spreading ubiquitously and invisibly in our daily lives and in industrial workplaces (Weiser et al. 1999). Ubiquitous computing has influenced other research topics such as mobile computing, wireless sensor networks (Dargie and Poellabauer 2010), and artificial intelligence (McCorduck 2004).

Ubiquitous computing operates as a rationale for the trend of transplanting "smartness" into everyday artifacts, which can be defined as "a non-computational physical entity with established purpose, appearance and use in everyday experience" (Beigl et al. 2001). Instead of inventing new artifacts with computational intelligence, everyday artifacts can become smart objects (SOs) when they augmented with the ability to gather, process and 
exchange digital information. The objects' original appearance and functions remain uncompromised by this value adding (Beigl et al. 2001).

Various definitions of SOs have been proposed. For example, López et al. (2012) define SOs as objects that are not only capable of providing their unique identification and condition information, but can also perform object-to-object communications, ad-hoc networking and object-centric complex decision-making. A SO is an object that enhances interaction with people and with other SOs (Holmquist et al. 2001; Moawad et al. 2012), deviating from the people-centric decision-making model. Kortuem et al. (2010) suggested that SOs carry chunks of application logic that let them make sense of their local situation and interact with human users. They sense, log, and interpret the occurrence of themselves and the world, act autonomously, communicate with each other, and exchange information with people. Zhang et al. (2011) define SOs as physical manufacturing resources that are made "smart" by equipping them with Auto-ID devices, e.g. radio-frequency identification (RFID) devices.

A consensual typology of SOs is yet to be agreed but efforts have been paid to developing it. According to some researchers, SOs can be smart physical objects or smart virtual objects (Kallmann and Thalmann 1999; Poslad 2009). Kortuem et al. (2010) advocate the dual nature of SOs as real world entities and their digital representations. Zhang et al. (2011) name SOs with RFID readers "active SOs" (e.g. work stations and forklifts), and those with RFID tags "passive SOs" (e.g. tagged materials, pallets). Streitz et al. (2005) classify the smartness of SOs into two types: system-oriented and people-oriented. System-oriented SOs can take self-directed action or issue alerts when sensing parameters that are invisible or otherwise non-perceptible to human beings, e.g. minor vibrations. 
People-oriented SOs, on the other hand, are intended to help people make better decisions by aggregating data and communicating it to them intuitively.

The concept of "smart objects" is developing along with their unique properties, beginning with two properties not possessed by traditional computers or traditional everyday objects: context awareness and ad hoc information-sharing ability (Beigl et al. 2001). Context awareness reflects the ability of SOs to perceive their surrounding real-world environment (Beigl et al. 2001; Kortuem et al. 2007), and to sense, log and interpret what is going on in this environment (Kortuem et al. 2010). Ad hoc information sharing addresses the ability of a SO to share its awareness with other SOs via intercommunication or with people by transmission (Kortuem et al. 2007; López et al. 2012; Mattern 2003).

Besides these two core properties, other functions of SOs include traceability, retentiveness, and autonomy. Mattern (2003) proposes that a SO may be able to proactively report its real-time location or have tracking enabled (e.g. by carrying RFID tags). On top of SOs' self-awareness and networking ability, he stresses their potential capability to keep track records. Based on history data collected, SOs could achieve autonomy, taking particular corresponding actions when reaching a certain threshold (Kortuem et al. 2007). López et al. (2012) outline five fundamental properties underlying the development of SOs:

- Possessing a unique identity.

- Being able to sense and store measurements made by sensor transducers associated with them.

- Being able to make their identification, sensor measurements and other attributes available to external entities such as other objects or systems. 
- Can communicate with other smart objects.

- Can make decisions about themselves and their interactions with external entities.

\section{Smart objects in various industries}

Smart objects (SOs) have been defined and their potential explored in various industries. Table 1 is a summary of various studies on the applications of SOs. While not directing using the term "smart object", there have several studies proposing physical devices augmented with some kind of "smartness" using automation, sensing technology or other enabling technology to facilitate construction works (See Table 1). The potential of using these technologies have also been proposed and tested in different scenarios in the construction industry including supply chain management, on-site construction, facility management and safety management. These studies have addressed one or more properties that smart objects possess, including the autonomy to act, the awareness to capture real-time information and the ability to communicate.

<Table 1 here>

However, despite these research efforts, SCOs and their definition, properties, applications, representations, and prospects have never been systematically explored. Single or scattered smart objects that have been proposed are not enough to exert the full potential of smart objects. It is necessary to steer toward a panoramic and interconnected smartness in future construction practice. To do so requires examination of the inheritable properties of SOs from other industries and incorporation of properties addressing the heterogeneity of construction. 


\section{Defining smart construction objects}

Developing smart construction objects (SCOs) is a step towards ubiquitous computing and "smartness" in the construction context. SCOs are defined in this study as follows:

Construction resources (e.g. machinery, tools, device, materials, components, and even temporary or permanent structures) that are made "smart" by augmenting them with sensing, processing and communication abilities so that they have autonomy and awareness, and can interact with the vicinity to enable better decision-making.

Based on the literature review and the uniqueness of construction contexts, we have determined that a SCO must have three core properties: awareness, communicativeness and autonomy, as shown in Figure 1. As geometric or non-geometric information such as dimensions, materials, and manufacturers exist in every construction object, these properties are not included in Figure 1.

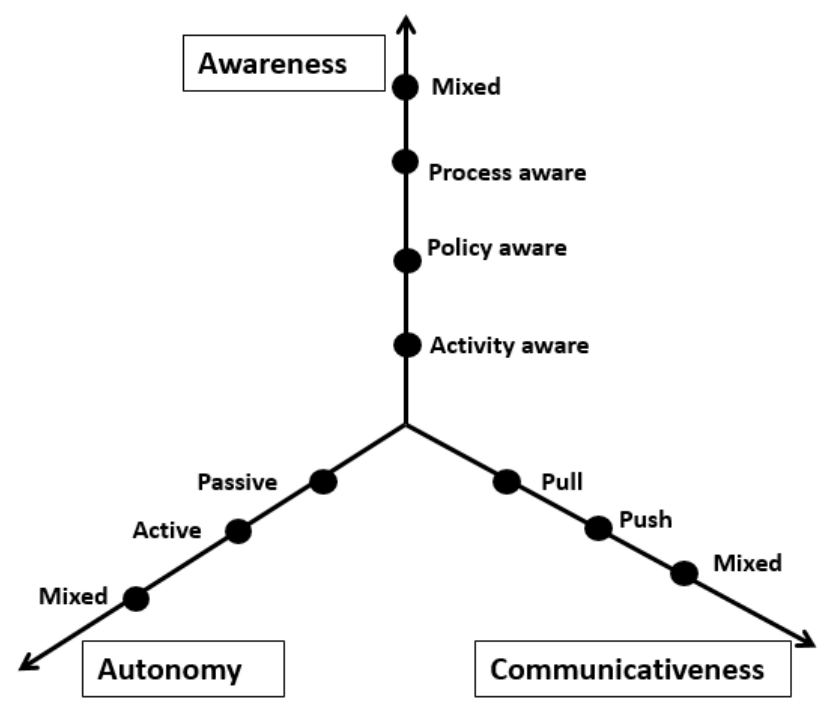

Figure 1. Three core properties of a SCO

\section{Awareness}


Awareness, the most distinct feature of SCOs compared to traditional construction objects, denotes SCOs' ability to sense and log their real-time condition and that of the surrounding environment. This property is based on the framework for smart objects proposed by Kortuem et al. (2010), which has three awareness dimensions: activity, policy, and process. Activity awareness is the simplest a SCO can possess. With this awareness, the SCO can understand and record certain types of activity or event related to its use and handling such as picking up, turning on, operating in particular ways, turning off, and so on. Policy awareness enables SCOs to understand to what extent a real-time condition or activity complies with rules and regulations. This awareness is extremely useful for guarding against threshold-breaking activities or environmental effects exceeding a preset tolerance range. Process awareness is a high-level awareness that helps SCOs recognize workflow and transition between construction activities. A process-aware SCO can offer assembly guidance when the default assembly position or operating path is in order and, when a contingency occurs, present the optimum working path by crosschecking the real-time process with default workflow. Currently, SCO awareness can be realized using sensing or positioning technologies.

\section{Communicativeness}

Communicativeness denotes the ability of a SCO to output information it has obtained through its awareness. Communication between a SCO and managerial personnel or among SCOs can be conducted through information "pull" or "push" modes. Information pull occurs upon request; the information is communicated only when people or SCOs ask for specific information from an information bearer. For example, a foreman could check the total use hours of a smart tool when renting and returning that tool. In information push mode, SCOs proactively send updated information or issue alerts at regular intervals 
or on an ad hoc basis to a recipient. Information push can be of great help when continuous monitoring (e.g. of temperature or moisture content) is needed. There are many communication technologies currently available such as Wi-Fi, Bluetooth, ZigBee, near field communication (NFC), and Internet-based services; ad hoc networking, meanwhile, is an emerging and promising direction for enhancing SCO communicativeness.

\section{Autonomy}

Autonomy refers to the ability of a SCO to take self-directed action or alert people for further action based on preset rules. Autonomy can be seen as another means of information output. Sometimes an instant reaction is needed, particularly in an emergency, yet the response of personnel may lag. Passive autonomy aims to assist people in making decisions and taking actions, and enables a SCO to issue an alert seeking a response from managerial personnel, warning on-site workers, or even providing an optimum plan. A SCO with active autonomy, on the other hand, could form an action plan based on the real-time situation it senses and actually executes this plan, without including humans in the loop. For example, an on-site construction plant may turn off automatically when it is about to reach an overloading current. Realization of SCO autonomy is dependent on various application logic or reasoning algorithms.

The three core SCO properties of awareness, communicativeness, and autonomy usually function in cooperation. Each type of the awareness, communicativeness, and autonomy is not fixed to a one-to-one correspondence. Instead, different types of core properties may combine together to function, depending on the needs and requirements of different circumstances. In more complex scenarios, it is also possible that the cooperation of more than one type of awareness, communicativeness, or autonomy is needed. This "mixed" 
mode, where more than one type of property is involved, is plotted in Figure 1. It is also possible, however, that properties more advanced than the three core properties will be created in the future.

\section{Example scenarios of using smart construction objects}

This section illustrates the wide application of SCOs and their smart properties with four example scenarios: construction logistics and supply chain management, safety management, procedure guiding, and facilities management.

\section{Construction logistics and supply chain management}

Construction logistics and supply chain management (LSCM) is often critical to achieving project management objectives such as on-time delivery, cost saving, and meeting quality standards (Vrijhoef and Koskela 2000). In practice, construction LSCM is very complicated, involving multiple parties in the processes of production, warehousing, transportation, temporary storage in multiple transfer depots, and finally use on-site. It is even more challenging nowadays as the sources of materials are geographically dispersed, leading to a prolonged logistics and supply chain along which new standards (e.g. lower carbon emissions, increased social responsibility) have been applied. In addition, construction sites are often confined spaces in which the placement of materials and machinery must be very carefully planned. In extreme cases, project managers have to adopt a "just in time" (JIT) system in their LSCM. It is not uncommon for high costs and serious delays to result from a shortage of materials, or when an on-site warehouse runs out of space due to an overly stockpiled inventory. To avoid these occurrences, project managers need real-time information traceability and visibility of materials/components

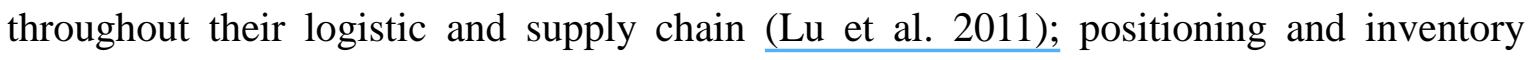


information in particular.

The development of SCOs can enhance construction LSCM. As shown in Figure 2, activity awareness can be embedded in transported materials, transporting vehicles, and checkpoints (e.g. warehouse gates, customs, or site entrances), turning these resources into SCOs. Through interactions (e.g. a smart component talking to the warehouse gate), real-time location information can be recorded and communicated to other SCOs throughout the logistics and supply chain. What is more compelling is the idea that SCOs could actively generate inventory dynamics information. With activity awareness, smart vehicles could read and log information at loading and unloading. When entering and leaving a transfer depot, the inventory could be updated by the SCOs exercising active autonomy. For example, when the inventory is lower than a preset volume the SCOs could make an order. Procurement managers could then be relieved of routine, tedious and time-consuming processes subject to human error.

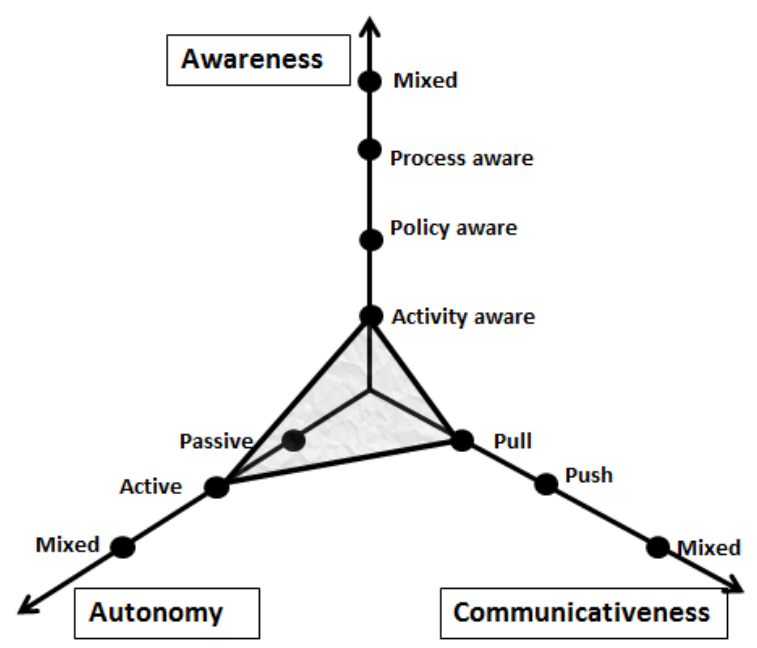

Figure 2. SCO property diagram for component tracking scenario

\section{Safety management}

Construction is notorious for it being a 3D (dangerous, dirty, and demanding) industry 
(Construction Industry Steering Committee, 1999). There are numerous hazards on a construction site, lack of awareness of which can cause serious and even fatal accidents, such as falls from height or being hit by construction materials or machinery approaching from behind (Abdelhamid and Everett 2000). There are non-perceptible environmental factors, such as the presence of particulate matter in the air that can lead to chronic disease such as pneumoconiosis or asbestos-related lung cancer. Noise and vibration can also have serious effects upon the health of construction site workers. Construction safety management is thus a topic that has long concerned researchers and project managers. It is desired that hazards be closely monitored and, whenever possible, action taken autonomously before any harm is caused to construction personnel, who may not themselves respond swiftly to emergent hazards.

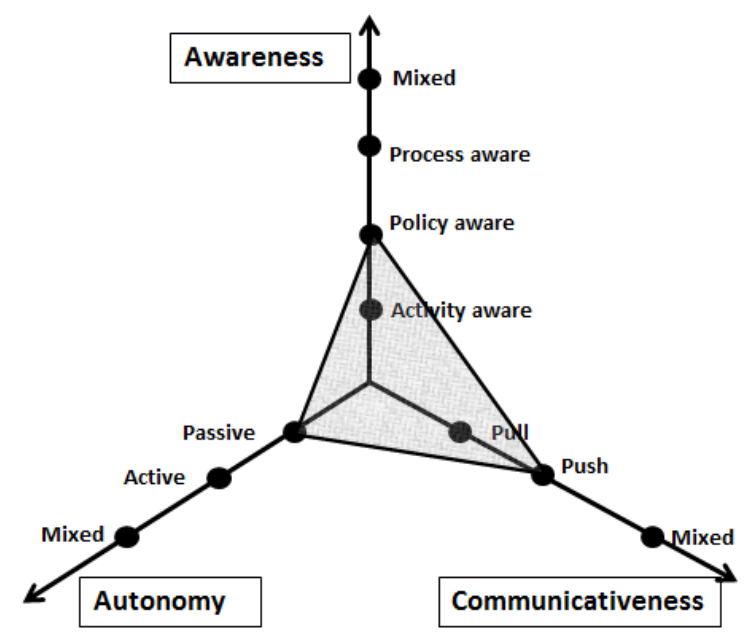

Figure 3. SCO property diagram for safety management scenario

The development of SCOs can enhance construction safety. For example, as shown in Figure 3, maximum human-bearing thresholds could be input into smart tools, helmets, and other wearable devices. Augmented with policy awareness, these SCOs can sense environmental conditions. If conditions are below threshold, the SCOs could perform 
"information push" to the user interface for monitoring. If the threshold is broken, the SCOs could issue automatic alerts. For example, a smart helmet could detect the direction and velocity of an approaching item and, based on established policies, determine the hazard level. A smart crane tower could calculate its loading limits and respond autonomously. As a result, operators may examine, repair or replace a new device before any hazard occurs. While technologies in these scenarios could diverge (e.g. ultra-wideband wave or Wi-Fi signal for safety helmets), all can be generalized to canonical SCOs with policy awareness, "mixed" autonomy, and "push" communicativeness.

\section{Procedure guiding}

SCO process awareness is particularly useful for guiding delicate workflow on-site, such as assembly of prefabricated components or cooperation between different construction trade plants. Workflow consists of activities that are linked by transition point (Kortuem et al., 2010). At every transition point, a SCO may redirect the workflow based on information from sensors or human input. Therefore, smart prefabricated components may guide assembly process operators to locate the precise assembly location and to avoid possible clashes. Exhibiting active autonomy, augmented machines and plants may exchange information and work status by pulling information from each other, and then cooperate by establishing a connection. After sharing information SCOs could, in an act of passive autonomy, jointly make suggestions to an operator for further action. Thus SCOs under the procedure-guiding scenario possess a mixed type of autonomy (See Figure 4). 


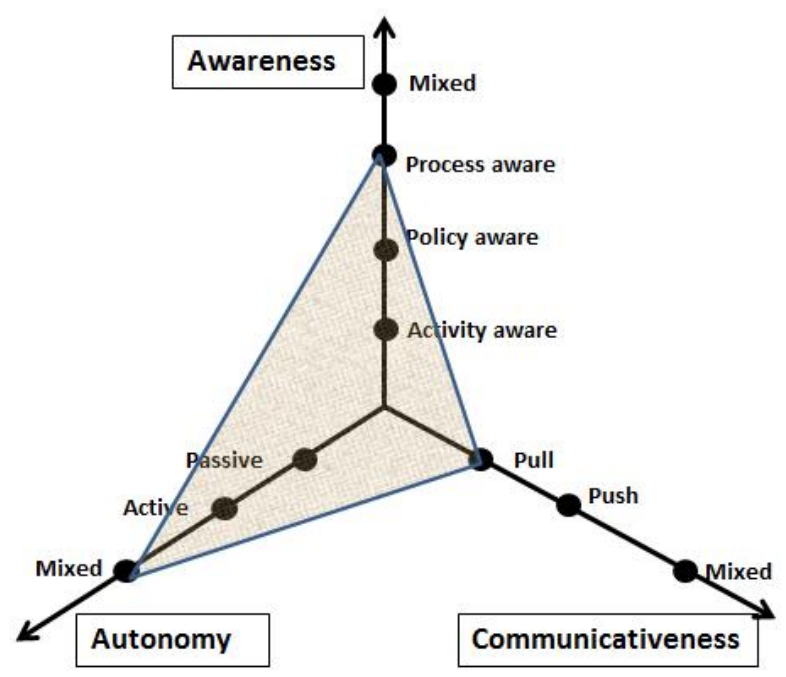

Figure 4. SCO property diagram for procedure-guiding scenario

\section{Facilities management}

SCOs that have been augmented with smartness and installed during the construction stage can be passed to the next stage to enhance facility management (FM). FM is a profession encompassing multiple disciplines and ensures functionality of the built environment by integrating people, place, process and technology (Tay and Ooi 2001). Building maintenance, which is concerned with maintenance of the designed functionality of a facility (in terms of accommodating people and their processes), is a crucial part of FM. To facilitate building maintenance, construction resources such as buried assets or building components will be turned into SCOs by augmenting them with "smartness". For example, after completion of construction work, the condition of buried assets such as piles and foundations is difficult for human inspectors to monitor. However, policy awareness could be embedded into these construction objects to allow sensing of real-time locations, particularly in cases where the foundation base is poor or subject to frequent earthquakes. When the shifting or settlement effect reaches a preset threshold, alerts can be issued so that there is sufficient time for maintenance or evacuation. For monitoring purposes, SCOs under the FM scenario may possess a mixed type of communicativeness (see Figure 5). In 
normal working conditions, SCOs could push information on the real-time status of the facility at regular intervals or via $a d-h o c$ networking. A facility manager would also be able to access status reports at particular time points.

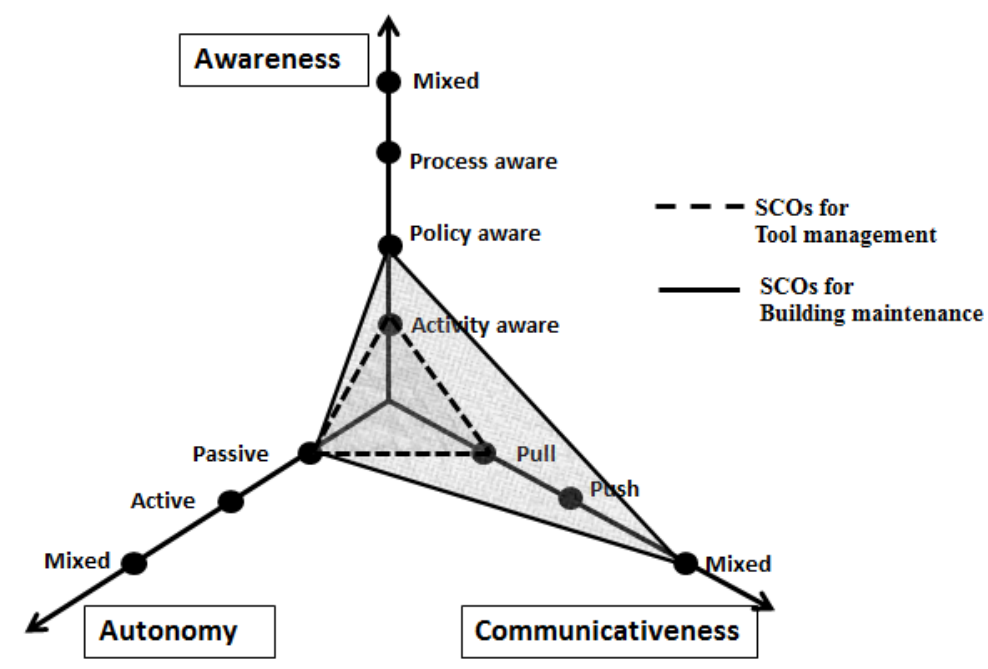

Figure 5. SCO property diagram for facility management scenario

The above example scenarios, illustrating the potential applications of SCOs and their smart properties, are by no means exhaustive. There are numerous construction scenarios, on-site or off-site, requiring the augmented capabilities of sensing, processing, computing, networking, and reacting to alleviate human beings' incapability in decision-making. The purpose of this section is to articulate a canonical SCO and its core properties for various computing applications. The SCO, therefore, has not been explored to an extent that it can be readily applied to the example scenarios. Next section is to explore the representation of SCOs by using an example which can be perceived as a synergy of the scenarios of LSCM, construction safety, and procedure guiding.

\section{Smart construction objects representation: an example}

To further explore the presentation of a smart construction object (SCO), a prefabricated 
concrete façade was chosen as representative components in prefabricated high-rise building production (See Figure 6). Basic parameters (dimensions, weight, materials, manufacturer, etc.) and assembly instructions (special fitting position, floor-ceiling height restriction, etc.) are embedded in the smart core of the façade at prefabrication stage. The smart prefabricated façade is then embedded with mixed awareness; activity awareness and process awareness. With the former, the façade can sense and record each connection it makes to the warehouse, transporting vehicles, and the tower crane, all of which have also been transferred into SCOs by augmenting with smartness. The latter enables the façade to guide assembly on-site. With mixed communicativeness, the logistics track record can be accessed whenever necessary. Meanwhile, once connected with the smart tower crane or other smart operating device, the façade can push default information to the user interface for operator reference. The following steps demonstrate the design and planning process for production of this smart prefabricated façade.

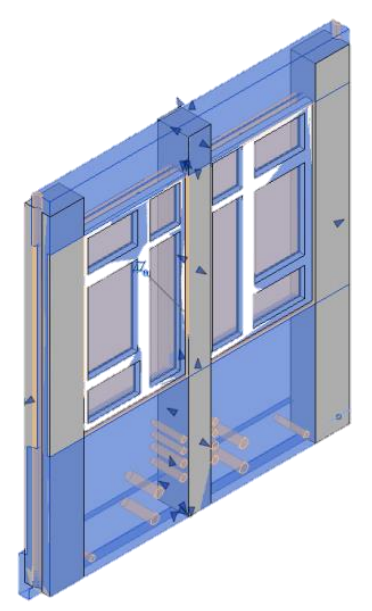

Figure 6. Designed model of a smart prefabricated façade

Firstly, the concrete façade block (as shown in Figure 6) is designed using available 3D design software such as ArchiCAD or Autodesk Revit. The façade is designed with necessary space and holes reserved for windows, reinforcement bars and the smart core. In addition to the basic design parameters and assembly requirements, the smart properties 
are also defined when establishing the virtual object. To represent the smartness of the SCO, IFC (Industry Foundation Classes) format is adopted. This is a standard, open data schema developed by buildingSMART with a view to enhancing the interoperability of software in the construction industry (Bazjanac and Crawley 1997). IFC format covers means to define building objects, processes, costs, schedules and other attributes from inception to completion of construction projects (Eastman et al., 2009). In this case study, the smart prefabricated façade is written in ifcXML format. IfcXML files are XML documents that represent the same contents of the IFC file (buildingSMART 2015). Here, ifcXML has been added as a valid representation of IFC schema since there are plenty of available tools and toolkits for writing, reading and transforming XML files (buildingSMART 2015).

Figure 7 shows an ifcXML file containing a portion of information about the smart prefabricated façade. Information attributes describing who created and last modified the object are stored in the OwnerHistory tag under IfcRoot. Parameters and properties of the façade can also be restricted for editing by a read-only marking. Details of the SCO properties are described and stored in the IfcApplication tag, since this holds the information about an IFC-compliant application. Realization of SCO properties can be supported by the smart core; that is, embedded operating application programs and hardware components. In this case, for example, communicativeness for the façade is achieved through a Bluetooth connection. The IfcXML tags store information describing applications to activate the Bluetooth module, to set up communicating connections, and for parameters to be pulled from the façade. This information is then decoded by applications in the smart core and operated by Bluetooth modules and other necessary components. The properties of awareness and autonomy are pre-described and preset in 
IfcXML format in the same way as communicativeness.

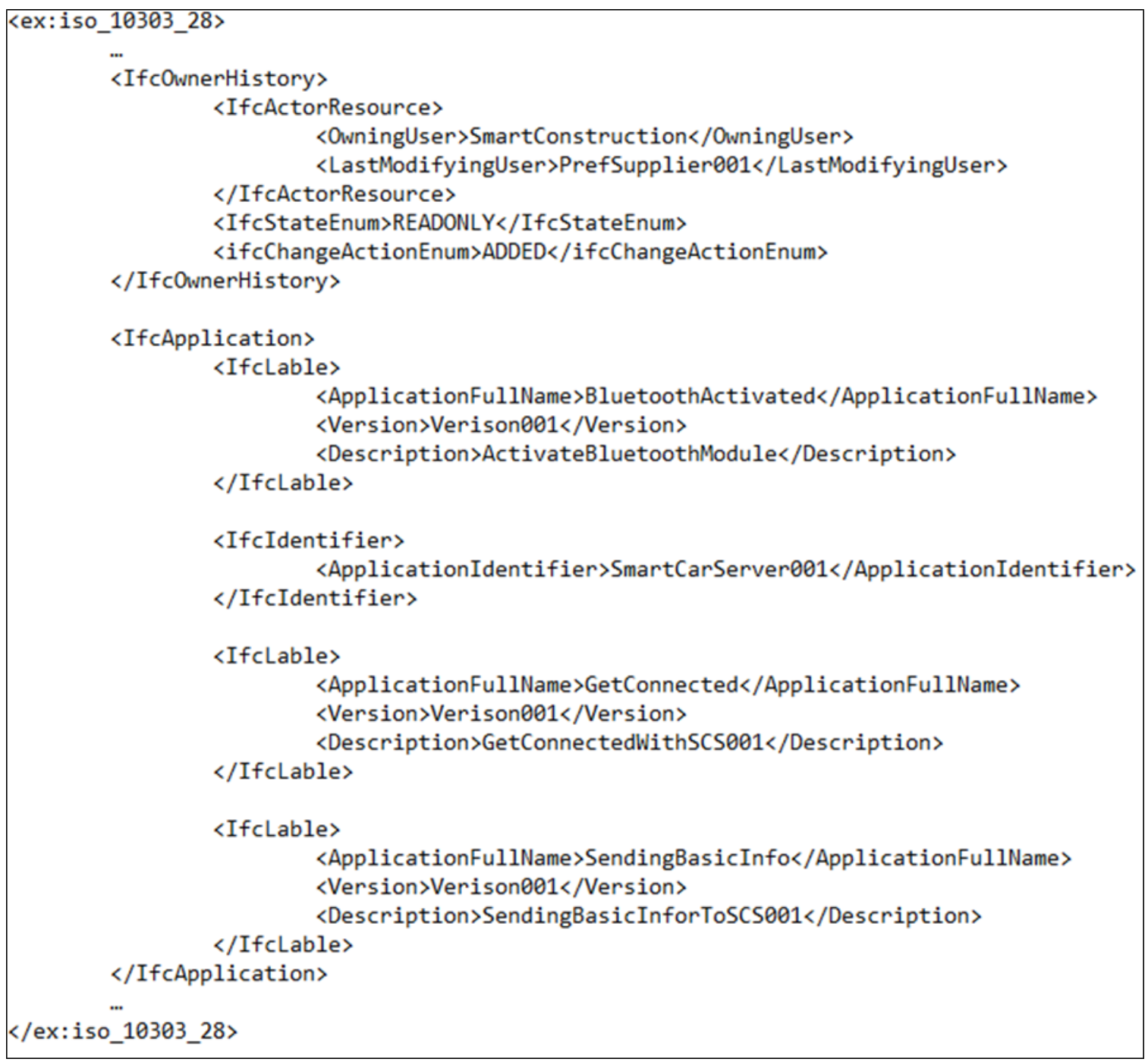

Figure 7. Part of the ifcXML file containing the parameters and properties of a smart prefabricated façade

Secondly, the hardware serving as the smart core of the façade is designed according to the ifcXML definition of the façade. Power, sensors, and general input/output modules such as Bluetooth, memory and other necessary components are assembled in a tailor-made fashion in the smart core, which also stores information about the façade including basic parameters and assembly requirements. The smart core is then sent to the prefabrication factory for insertion during the façade prefabrication process. 
Lastly, the smart prefabricated façade is transported to the construction site. With its property of awareness, the façade can report its real-time positions and status. This information is critical for enhancing logistics and supply chain management in housing production. Figure 8 demonstrates the intended assembly workflow of the smart prefabricated façade. After the Bluetooth modules have been paired and activated, the smart façade and the smart tower crane can connect and communicate. The assembly guidelines (e.g. position, hoisting path) for the façade are automatically pushed to the smart user interface installed in the cockpit of the tower crane, so as to inform the operator about the façade and guide assembly. In addition, by embedding the crane tower with some simple preset rules, the crane tower can autonomously determine whether it is safe to hoist a certain façade.

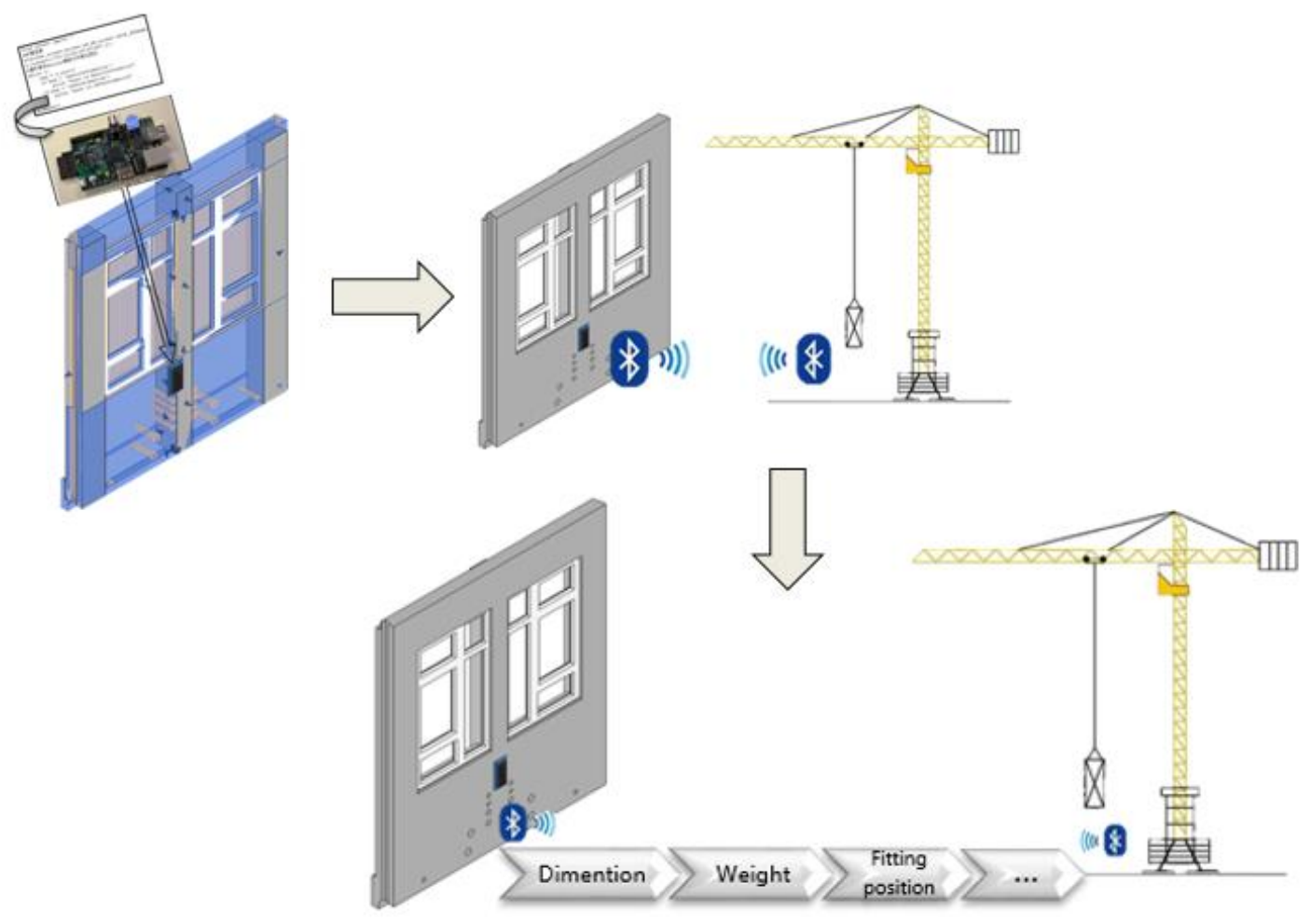

Figure 8. Intended workflow for smart prefabrication façade assembly

We have presented the SCO representations in various occasions and attracted 
considerable attentions from construction industrialists. A real-life public housing building in Hong Kong, together with its prefabrication yard and logistic services, has been chosen as a case study. Hardware and software solutions to realize the functionality of the SCOs are under development. In fact, some of the smart technologies such as on-site locationing for awareness, ad-hoc networking for communicativeness, and robots/mechanical arms for autonomy are remaining the major challenges for construction researchers and practitioners around the world. Bearing in mind the research aim to articulate a canonical SCO and its core properties and representations for various computing applications, the detailed solutions and validations are not reported in this paper but designated as future studies.

\section{Discussion}

The importance of information cannot be overemphasized in contemporary construction project management, which essentially can be perceived as making a web of decision based on the information available. Existing models for decision-making in construction are, by and large, people-centric; it is human decision-makers who are responsible for the use (or misuse) of construction resources. These people-centric models, however, ignore the potential of artificial intelligence (AI) to be more accurate, precise, and swift in managing information, and thus to enable better decisions in some scenarios. With "smart" properties such as awareness, communicativeness, and autonomy, smart construction objects (SCOs) can contribute to data collection and information processing, and even make autonomous decisions. In doing so, SCOs can eliminate human errors in the loop and save time and labor. They are able to collect real-time information, provide informative feedback, and perform automatic actions, all without changing their original appearance and functions in construction. 
SCOs represent an immense opportunity to improve the global construction industry. SCOs could significantly enhance the power of building information modeling (BIM), which has been widely advocated as a means of improving interoperability (Eastman et al. 2009), communication (Fischer and Kunz 2004), and facilitating information and knowledge management ( $\mathrm{Li}$ et al. 2009). Most existing building information models are constructed from an "as-design" condition, with variations and changes tending to occur in the subsequent construction and operation stage (Tang et al. 2010). To make building information model a truly useful information hub for decision-makers, "as-built" information is needed to update the model. Currently, as-built verification and updates are mainly based on manual on-site surveys, which are time-consuming and error-prone (Klein et al. 2012). In a sense, BIM development has reached a bottleneck without "as-built" information being synchronizing with BIM in a real-time manner to truly support decision-making. The invention of SCOs offers a superior means of bridging the information gap between the "as-building" situation and the building information model. The awareness of SCOs means that they can continuously gather real-time information about their physical state and vicinity, while the property of communicativeness enables SCOs to synchronize "as-built" information with a building information model in a more proactive, frequent, comprehensive, and precise manner.

Moreover, a SCO could directly serve as a virtual information-rich element in a BIM-based system. Its information can be pulled out for review, exchange, or future planning. Properties of SCOs are defined and stored in ifcXML format, which can be linked seamlessly to existing BIM-based systems. Files adopting IFC schema can be recognized by most BIM-related software, facilitating better sharing and exchange of 
information between project stakeholders (Bazjanac and Crawley 1997; Eastman et al. 2009; Halfawy and Froese 2005). SCOs also reduce the amount of human intervention needed to reinterpret and reformat information when sharing building information models, thus reducing the possibility of error during data transformation (Halfawy and Froese 2005). It is envisaged that the invention of SCOs will break through the bottleneck confining BIM development and trigger another wave of opportunities to make BIM a truly helpful decision-support system.

Given the ability of SCOs to connect and communicate with each other, they also become the basic components in forming the Internet of Things (IoT); an emerging paradigm that has attracted considerable attention in the construction industry, particularly for construction LSCM and smart facilities. In the IoT paradigm, physical objects are connected at anytime and anywhere, requiring intelligence to be embedded not only in computers but also everyday objects (Gubbi et al. 2013). SCOs, as construction resources augmented with artificial intelligence, serve as elementary nodes in the construction IoT. The IoT can be perceived as a loosely coupled, decentralized system of SCOs. The awareness possessed by SCOs is a core element in the IoT vision, as context-awareness makes machine-to-machine communication easier and more meaningful (Perera et al., 2014). With the property of autonomy, SCOs can establish connections based on certain protocols, such as a distance-based trigger. Once the network is set up, information sensed by each SCO node can be shared within the Internet via the communicativeness of SCOs. With SCOs continuously sensing, logging, and sharing real-time information with each other, the network made up of SCOs can be maintained in an active status. SCOs sense, $\log$, and interpret their local situation, carry chunks of application logic, act on their own, intercommunicate with each other, and exchange information with people; a underpinning 
philosophy of IoT.

It is envisaged that SCOs will gradually supersede traditional construction objects to become the basic elements of construction in the future, but there are various challenges to be overcome. The first is likely to be a reluctance to deviate from the mindset of people-centric decision-making in order to embrace AI. Acceptance of SCOs will be challenged, particularly while their robustness is still to be enhanced. The second challenge will be interoperability of SCOs. The smartness of SCOs is largely dependent on the information exchange amongst them; without a SCO standard, there will be no interoperability and in turn no smartness (though currently SCOs can generally be expressed in ifcXML). An exacerbating factor is the highly fragmented nature of construction; no single group can be the driving force steering the industry towards technological advancement (Flanagan et al. 2014). The third challenge is the cost of developing SCOs. The construction industry is relatively sluggish to embrace the full potential of new technologies (Stewart et al. 2004), and organizations within the industry are particularly sensitive to IT expenditure, especially before they can identify a clear benefit (Peansupap and Walker 2006). Such conservative practice and cost-driven culture may hinder organizations from investing in SCOs.

\section{Conclusions}

The global construction industry which has long been plagued with problems such as delayed delivery, escalating cost, and unsatisfactory quality is calling for a paradigm shift from traditional architecture, engineering, and construction practices. This paper attempts to articulate a canonical SCO, which could potentially lead to such paradigm shift. Informed by theories on ubiquitous computing and general smart objects, smart 
construction objects (SCOs) are defined as construction resources (e.g. machinery, tools, device, materials, components, and even temporary or permanent structures) that are made "smart" by augmenting them with sensing, processing and communication abilities so that they have autonomy and awareness, and can interact with the vicinity to enable better decision-making. A SCO must have three core properties: awareness, communicativeness and autonomy. Each type of the awareness, communicativeness, and autonomy is not fixed to a one-to-one correspondence. Instead, different types of core properties may combine together to function, depending on the needs and requirements of different circumstances.

Equipped with these smart properties, SCOs are capable of sensing, computing, communicating, and taking action without necessarily involving humans in the loop. They can be applied to, inter alia, critical scenarios such as construction logistics and supply chain management, safety management, construction procedure guiding, and facilities management. SCOs thus represent enormous opportunities to improve the construction industry globally, particularly in conjunction with building information modeling (BIM) and the Internet of Things (IoT). Not only can they directly serve as virtual information-rich elements in a BIM-based system, but also can SCOs offer a superior means of bridging the information gap between the "as-building" situation and the building information model in a more proactive, frequent, comprehensive, and precise manner. With their smart properties, SCOs can act as elementary nodes in the construction IoT, whereby physical objects are connected at anytime and anywhere, requiring intelligence to be embedded not only in computers but also all these nodes to enable a more connected world. SCOs are even expected to be ubiquitously applied as the basic elements in future construction. 
Given the fact that SCOs are in the early days of their development, they are technical hurdles, e.g. on-site locationing for awareness, ad-hoc networking for communicativeness, robots/mechanical arms for autonomy, and interoperability and robustness of the technologies, making SCOs yet to be readily applicable in current construction practices. In addition to the hurdles, there are other non-technical challenges, in particular, acceptance of artificial intelligence, organization readiness, cultural changes, and the new cost to be overcome. Nevertheless, by overcoming these challenges, it is envisaged that SCOs will enable a safer, greener, more efficient, and more effective construction industry which has never been seen before.

\section{Acknowledgement}

This study is jointly supported by the General Research Fund (Project No.: 17205614) of the Hong Kong Research Grant Council (RGC) and the Innovation and Technology Fund (Project No.: ITP/045/13LP) of the Hong Kong Innovation and Technology Commission (ITC).

\section{References}

Abdelhamid, T. S., and Everett, J. G. (2000). Identifying root causes of construction accidents. Journal of Construction Engineering and Management, 126(1), 52-60.

Akhavian, R., and Behzadan, A. H. (2012). An integrated data collection and analysis framework for remote monitoring and planning of construction operations. Advanced Engineering Informatics, 26(4), 749-761.

Aziz, Z., Anumba, C. J., Ruikar, D., Carrillo, P. M., and Bouchlaghem, D. N. (2005). Context aware information delivery for on-site construction operations. In Proceedings of the 22nd CIB-W78 Conference on Information Technology in Construction, Institute for Construction Informatics, Technische Universitat Dresden, 
Germany, CBI Publication, 304, 321-332.

Bazjanac, V., and Crawley, D. B. (1997). The implementation of industry foundation classes in simulation tools for the building industry. Lawrence Berkeley National Laboratory.

Beigl, M., Gellersen, H.W., and Schmidt, A. (2001). Mediacups: experience with design and use of computer-augmented everyday artefacts. Computer Networks, 35(4), 401-409.

buildingSMART. (2015). General understanding of the IFC Specification. Retrieved 06 March, 2015, from http://www.buildingsmart-tech.org/implementation/faq/fag-general-ifc-spec.

Chen, K., Lu, W., Peng, Y., Rowlinson, S., and Huang, G. Q. (2015). Bridging BIM and building: From a literature review to an integrated conceptual framework. International Journal of Project Management, 33(6), 1405-1416.

Cheng, J., Bannach, D., Adamer, K., Bernreiter, T., and Lukowicz, P. (2008). A wearable, conductive textile based user interface for hospital ward rounds document access. Smart Sensing and Context, 182-191.

Cho, C. Y., Kwon, S., Shin, T. H., Chin, S., and Kim, Y. S. (2011). A development of next generation intelligent construction liftcar toolkit for vertical material movement management. Automation in construction, 20(1), 14-27.

Construction Industry Steering Committee. (1999). Re-inventing Construction: Construction 21. Ministry of Manpower and Ministry of National Development, Singapore.

Dargie, W., and Poellabauer, C. (2010). Fundamentals of Wireless Sensor Networks: Theory and Practice. John Wiley and Sons.

Domdouzis, K., Kumar, B., and Anumba, C. (2007). Radio-Frequency Identification 
(RFID) applications: A brief introduction. Advanced Engineering Informatics, 21(4), $350-355$.

Eastman, C., Jeong, Y. S., Sacks, R., and Kaner, I. (2009). Exchange model and exchange object concepts for implementation of national BIM standards. Journal of Computing in Civil Engineering, 24(1), 25-34.

Fischer, M., and Kunz, J. (2004). The scope and role of information technology in construction. Paper presented at the Proceedings-Japan Society of Civil Engineers.

Fitton, D., Sundramoorthy, V., Kortuem, G., Brown, J., Efstratiou, C., Finney, J., and Davies, N. (2008). Exploring the design of pay-per-use objects in the construction domain. Smart Sensing and Context, 192-205.

Flanagan, R., Jewell, C., Lu, W., and Pekericli, K. (2014). Auto-ID - Bridging the Physical and the Digital on Construction Projects. Chartered Institute of Building.

Flanagan, R., and Lu, W. (2008). Making informed decisions in product-service systems. Paper presented at the IMechE Conference, Knowledge and Information Management Through-Life, Institute of Mechanical Engineers, London.

Fuchs, S., Rass, S., Lamprecht, B., and Kyamakya, K. (2007). Context-awareness and collaborative driving for intelligent vehicles and smart roads. Paper presented at the 1st International Workshop on ITS for an Ubiquitous ROADS.

Goedert, J. D., and Meadati, P. (2008). Integrating construction process documentation into building information modeling. Journal of Construction Engineering and Management, 134(7), 509-516.

Gubbi, J., Buyya, R., Marusic, S., and Palaniswami, M. (2013). Internet of Things (IoT): A vision, architectural elements, and future directions. Future Generation Computer Systems, 29(7), 1645-1660.

Halfawy, M., and Froese, T. (2005). Building integrated AEC systems using smart objects: 
Methodology and implementation. Journal of Computing in Civil Engineering, 19(2), 172-181.

Holmquist, L. E., Mattern, F., Schiele, B., Alahuhta, P., Beigl, M., and Gellersen, H.-W. (2001). Smart-its friends: A technique for users to easily establish connections between smart artefacts. Paper presented at the Ubicomp 2001: Ubiquitous Computing.

Huang, G. Q., Zhang, Y., and Jiang, P. (2008). RFID-based wireless manufacturing for real-time management of job shop WIP inventories. The International Journal of Advanced Manufacturing Technology, 36(7-8), 752-764.

Hwang, S. (2012). Ultra-wide band technology experiments for real-time prevention of tower crane collisions. Automation in Construction, 22, 545-553.

Jaselskis, E. J., and El-Misalami, T. (2003). Implementing radio frequency identification in the construction process. Journal of Construction Engineering and Management, 129(6), 680-688.

Kallmann, M., and Thalmann, D. (1999). Modeling Objects for Interaction Tasks. Springer.

Kawakami, T., Ly, B. L. N., Takeuchi, S., Teranishi, Y., Harumoto, K., and Nishio, S. (2008). Distributed sensor information management architecture based on semantic analysis of sensing data. Paper presented at the Applications and the Internet, 2008. SAINT 2008, 353-356.

Klein, L., Li, N., and Becerik-Gerber, B. (2012). Imaged-based verification of as-built documentation of operational buildings. Automation in Construction, 21, 161-171.

Kolba, M. P., and Collins, L. M. (2006). Information-theoretic sensor management for multimodal sensing. Paper presented at the IEEE International Conference on the Geoscience and Remote Sensing Symposium, 2006. 3935-3938. 
Kortuem, G., Alford, D., Ball, L., Busby, J., Davies, N., Efstratiou, C., . . . Kinder, K. (2007). Sensor networks or smart artifacts? An exploration of organizational issues of an industrial health and safety monitoring system: Springer.

Kortuem, G., Kawsar, F., Fitton, D., and Sundramoorthy, V. (2010). Smart objects as building blocks for the internet of things. Internet Computing, IEEE, 14(1), 44-51.

Khoshnevis, B. (2004). Automated construction by contour crafting-related robotics and information technologies. Automation in Construction, 13, 5-19.

López, T. S., Ranasinghe, D. C., Harrison, M., and McFarlane, D. (2012). Using Smart Objects to build the Internet of Things. IEEE Internet Computing (to appear, 2013).

López, T. S., Ranasinghe, D. C., Patkai, B., and McFarlane, D. (2011). Taxonomy, technology and applications of smart objects. Information Systems Frontiers, 13(2), 281-300.

Li, H., Lu, W., and Huang, T. (2009). Rethinking project management and exploring virtual design and construction as a potential solution. Construction Management and Economics, 27(4), 363-371.

Li, Y., Feng, L., Qiao, L., Li, Y., Kong, S., Yi, Y., Qin, W. (2010). FireGuide: a context-aware fire response guide for the building occupants. Smart Sensing and Context, 1-14.

Louis, J., Dunston, P., Martinez, J., and West, S. M. D. (2014). Automating construction operations using discrete event simulation models. In Construction Research Congress 2014, 1043-1052.

Lu, W., Huang, G. Q., and Li, H. (2011). Scenarios for applying RFID technology in construction project management. Automation in Construction, 20(2), 101-106.

Mattern, F. (2003). From smart devices to smart everyday objects. Paper presented at the Proceedings of smart objects conference. 
McCorduck, P. (2004). Machines Who Think: Twenty-Fifth Anniversary Edition. Natick, MA: A. K. Peters, Ltd.

Min, J. U., \& Bjornsson, H. C. (2008). Agent-based construction supply chain simulator (CS2) for measuring the value of real-time information sharing in construction. Journal of Management in Engineering, 24(4), 245-254.

Moawad, A., Efthymiou, V., Caire, P., Nain, G., and Le Traon, Y. (2012). Introducing conviviality as a new paradigm for interactions among IT objects. Paper presented at the Proceedings of the Workshop on AI Problems and Approaches for Intelligent Environments.

Peansupap, V., and Walker, D. H. (2006). Information communication technology (ICT) implementation constraints: a construction industry perspective. Engineering, Construction and Architectural Management, 13(4), 364-379.

Perera, C., Zaslavsky, A., Christen, P., and Georgakopoulos, D. (2014). Context aware computing for the internet of things: A survey. Communications Surveys and Tutorials, IEEE, 16(1), 414-454.

Poslad, S. (2009). Ubiquitous Computing: Smart Devices, Environments and Interactions. Wiley Publishing.

Reason, J. (2000). Human error: models and management. BMJ, 320(7237), 768-770.

Shin, T. H., Chin, S., Yoon, S. W., and Kwon, S. W. (2011). A service-oriented integrated information framework for RFID/WSN-based intelligent construction supply chain management. Automation in Construction, 20(6), 706-715.

Simon, H. A. (1986). Rationality in psychology and economics. Journal of Business, 59, S209-S224.

Sterman, J. D. (1989). Modeling managerial behavior: Misperceptions of feedback in a dynamic decision making experiment. Management Science, 35(3), 321-339. 
Stewart, R. A., Mohamed, S., and Marosszeky, M. (2004). An empirical investigation into the link between information technology implementation barriers and coping strategies in the Australian construction industry. Construction Innovation, 4(3), 155-171.

Streitz, N. A., Rocker, C., Prante, T., van Alphen, D., Stenzel, R., and Magerkurth, C. (2005). Designing smart artifacts for smart environments. Computer, 38(3), 41-49.

Tang, P., Huber, D., Akinci, B., Lipman, R., and Lytle, A. (2010). Automatic reconstruction of as-built building information models from laser-scanned point clouds: A review of related techniques. Automation in Construction, 19(7), 829-843.

Tatari, O., \& Skibniewski, M. (2006). Integrated agent - based construction equipment management: Conceptual design. Journal of Civil Engineering and Management, 12(3), 231-236.

Tay, L., and Ooi, J. T. (2001). Facilities management: a "Jack of all trades"? Facilities, 19(10), 357-363.

Torrent, D. G., and Caldas, C. H. (2009). Methodology for automating the identification and localization of construction components on industrial projects. Journal of Computing in Civil Engineering, 23(1), 3-13.

Vrijhoef, R., and Koskela, L. (2000). The four roles of supply chain management in construction. European Journal of Purchasing and Supply Management, 6(3), 169-178.

Weiser, M., Gold, R., and Brown, J. S. (1999). The origins of ubiquitous computing research at PARC in the late 1980s. IBM Systems Journal, 38(4), 693-696.

Werfel, J., Petersen, K., and Nagpal, R. (2014). Designing collective behavior in a termite-inspired robot construction team. Science, 343(6172), 754-758.

Zhang, Y., Huang, G. Q., Qu, T., Ho, O., and Sun, S. (2011). Agent-based smart objects 
management system for real-time ubiquitous manufacturing. Robotics and Computer-Integrated Manufacturing, 27(3), 538-549. 